\title{
Investigation of British Columbia Entrepreneurs' Secondary Market Research Habits and Information Needs
}

\author{
ALEHA MCCAULEY \\ University of British Columbia, Vancouver Campus \\ aleha.mccauley@ubc.ca \\ IRENA TREBIC \\ University of British Columbia, Vancouver Campus \\ irena.trebic@ubc.ca \\ KIM BUSCHERT \\ University of British Columbia, Okanagan Campus \\ kim.buschert@ubc.ca \\ NICK ROCHLIN \\ University of British Columbia, Okanagan Campus \\ nick.rochlin@ubc.ca \\ LAURA THORNE \\ University of British Columbia, Okanagan Campus \\ laura.thorne@ubc.ca
}

\begin{abstract}
Entrepreneurial research is of increasing significance to North American universities. University libraries have developed or enhanced services and supports for entrepreneurial researchers, to differing degrees. Currently, University of British Columbia (UBC) Library offers secondary research support to both campus and community entrepreneurs. In fall 2017, UBC librarians conducted a study in order to better understand the research habits and informationrelated needs of entrepreneurial researchers, as they relate to the development of business ventures at UBC and in British Columbia. The findings present opportunities for UBC librarians to create innovative services to attract and engage with entrepreneurs more completely. In order to meet the needs of BC entrepreneurs, possible considerations include targeting early-stage entrepreneurs (especially for library workshops), exploring access options and collections for entrepreneurs, developing and promoting online services, and having a service model with a single service entry point for entrepreneurs. Thorough marketing of entrepreneurial services is needed to ensure that the library is seen as a valuable resource. In addition to developing services and collections, forming partnerships with campus groups, community agencies and business groups is another way to increase awareness of library support for entrepreneurs.
\end{abstract}

Keywords entrepreneurship, small business, secondary market research, libraries, business education; business research, collaboration, academic business libraries, business schools 
In recent years, entrepreneurship education has grown dramatically in enrollment, number of courses available and participating programs (Torrance, 2013), while also undergoing a continual maturation in how it is taught (Neck \& Greene, 2011). Many North American universities provide entrepreneurship education as a campus-wide priority, from their designated business schools, or a hybrid of both (Torrance, 2013). Entrepreneurship education is interdisciplinary and often includes both curricular and non-curricular learning opportunities (Lackéus \& Williams Middleton, 2015). At the University of British Columbia (UBC), accelerator programs and seed funds for local entrepreneurs have been offered through various campus-wide and discipline-specific initiatives such as Entrepreneurship at UBC (e@UBC). Curriculum-based introductions to entrepreneurship and business venture development as well as extracurricular activities for students interested in this area are delivered through the UBC Sauder School of Business (Faculty of Commerce) and cross-listed Applied Sciences courses (Vancouver campus) and the Faculty of Management (Okanagan campus). Additional faculties, such as Engineering, Forestry and others, on both campuses, may assign business plans or business venture design activities in courses.

University Libraries have developed or enhanced services and supports for entrepreneurial researchers to differing degrees. Currently, UBC Library offers secondary research support to both campus and community entrepreneurs in the form of workshops, consultations, access to market research reports, and library collections and curated online business information, including research guides and websites such as sba.ubc.ca. Entrepreneurs conducting research at UBC experience unique challenges. Some library-licensed databases restrict access to users whose status is current student, faculty or staff member. Non-UBC researchers may also be restricted from booking spaces within UBC libraries.

In fall 2017, UBC librarians conducted a study in order to better understand the research habits and information-related needs of entrepreneurial researchers as they relate to the development of business ventures at UBC and in British Columbia. Results of the study may inform considerations for future service such as determining what forms of secondary market research (SMR) assistance UBC Library could provide, as well as informing collections offerings at UBC Library, in addition to potentially having an impact on licensing negotiations.

\section{Literature review}

This literature review sought to investigate entrepreneurs' information needs, information seeking behaviors, and the ways in which libraries can and currently are supporting entrepreneurs.

Information needs and behaviors of entrepreneurs. Thinking about entrepreneurs' activities can provide a useful framework to understand their information needs, because entrepreneurs' information seeking behavior is in large part dictated by the stage and state of their business (Shabaya, 2014; Głodek, 2018), as well as the amount of time available to find resources (Erzetič, 2008). The Panel Study of Entrepreneurial Dynamics concretely measures activities that entrepreneurs potentially perform during the start-up process. In the most recent version (2005-2011), 34 activities are included, from the most prevalent activity, "serious thought given to the start-up" (100\% of respondents), to collecting information on competitors (49\%), developing financial projections (31\%), and hiring an accountant (17\%) (Reynolds \& Curtin, 2011, p. 283). Entrepreneurs require education on business management and information on products and markets, and their needs might change if they have assistance to review their self-determined needs; for instance, entrepreneurs might position their idea as further along in 
readiness towards launch than it actually is, and therefore have more research or development needs to address (Yusuf, 2010). Jiao, Cui, Zhu and Chen summarize innovation-related needs as "introducing new products, applying new production methods, finding new markets, capturing new resources of, and setting up new industrial organisations" (2014, p. 503).

Each entrepreneurial venture is idiosyncratic. Information seeking behavior by entrepreneurs, then, may be defined as "the concrete enactment of an individual task or activity required to initiate, grow, or transform a business venture" (Mueller, Volery \& von Siemens, 2012, p. 996). Behaviors may change depending on the specific stage of the business (Shabaya, 2014). Fust, Wustrow and Fueglistaller developed a scale based on four types of previously identified information searching: "problemistic" searching involves seeking a solution to an identified need; "passive" information acquisition occurs when no distinct need exists; "proactive" searching is broader, seeking to define the market and its opportunities; and "systematic" searching incorporates sources the entrepreneur has used before (2015, pp.1-2).

In terms of acquiring information, entrepreneurs often attend short professional development courses and read professional literature, while along with these, formal education in a degree program may be pursued by owners heavily invested in growing their business (Erzetič, 2008). "Scanning and search" of materials such as news and trade sources can stimulate "creative behaviors" in support of change (Tang, 2016, pp. 1172-1173)

Developing and accessing a network can help entrepreneurs in many ways at various stages in the development of their ventures. For example, entrepreneurs may rely heavily on personal networks to start a business and then need to grow these networks to accommodate the need for different resources as their business grows (Sullivan \& Ford, 2014). Furthermore, it is quite common for entrepreneurs to seek external expertise that was recommended by someone already within their network (Sullivan \& Ford, 2014). Expertise from networks and business specialists helps entrepreneurs stay current, solve specific problems, and get feedback on ideas (Shabaya, 2014; Soetanto, 2017). It has been recommended that trust provides a factor in network maintenance; the resource requirement to keep up the network relationships dictates that networks be limited to trusted participants, thus ensuring easier access to knowledge (Yin \& Jahanshahi, 2018).

Library services for entrepreneurs. Libraries' key efforts to assist entrepreneurs entail developing "partnerships and connections with the business community" (Feldmann, 2014, p. 111). These outreach efforts can bring together libraries, community agencies, and campus departments (Griffis, 2015). Libraries, both public and academic, offer a wide variety of services to assist entrepreneurs in their business endeavors. Many libraries offer similar services, such as access to specialized business librarians, research guides, and software. An aspect that separates academic library business services from those of public libraries and community agencies is the "breadth and depth of specialized online databases, as well as specialized subject research experts available for individualized research assistance by appointment" (Griffis, 2015, p. 462). However, some public libraries are providing specialized software such as GIS (Collins, 2012; Enis, 2012). Hoppenfeld and Malafi (2015) describe myriad ways libraries are participating in the business community, including outreach efforts, embedding in business support enterprises, networking, and providing programs. A study of information types most requested by entrepreneurs in public libraries found the top five types were financial assistance, skills development or training, competitors, business plan writing, and market research (Franks \& Johns, 2015). The study 
Ticker: The Academic Business Librarianship Review, 5:1 (2020)

https://doi.org/10.3998/ticker.16481003.0005.107

(C)2020 Kim Buschert, Aleha McCauley, Nick Rochlin, Laura Thorne, and Irena Trebic

concluded that the libraries in their study were able to satisfy most needs, with the one exception being business consulting services, which were beyond the libraries' scope of expertise (Franks \& Johns, 2015).

The literature informed the design of our study in that we were able to include terminology and examples to survey British Columbia entrepreneurs about their current and desired means of acquiring information and business support.

\section{Study Purpose \& Objectives}

This study investigated the secondary market research habits and information seeking behavior of entrepreneurs in British Columbia, Canada. Specifically, it sought to ascertain the type of information entrepreneurs require to meet their needs; how they access information, advice and training; what reasons prompt them to seek research assistance for information; where they obtain information; and the challenges they face.

We intended this investigation to help UBC Library identify opportunities for improvement or changes with regard to research assistance, market research, and collection development. We also wanted to learn more about other potential services currently not available that these British Columbia entrepreneurs suggested would be important in supporting them. Because it was determined to be a quality improvement study, this investigation did not require review by UBC's research ethics board.

\section{Methodology}

In the fall of 2017, the researchers used an Internet-based survey to collect data on the role of the library, including its research services, collections, and related activities, that currently support BC entrepreneurs' educational and research experiences. The following describes the sampling process, data, and data analysis activities used. We would like to thank Carey Toane and Helen Kula at the University of Toronto, for sharing with us their survey instrument inquiring into campus entrepreneurs' research habits and needs.

Sampling. The researchers chose to use a non-probability sampling design, using availability sampling by defining a target population that was able to self-select (Daniel, 2012). This may also be considered volunteer sampling, as participants received a call to participate (via email and social media channels) and were able to decide whether or not to voluntarily engage. Several types of participants were sought for this study. The following outlines the criteria for each participant group:

Researchers who live in British Columbia that:

- have a product or service they are seeking to take to market, or

- are enrolled in an entrepreneurship course or program, or

- have research or intellectual property they are in the process of commercializing, or

- have participated in an incubator, accelerator, or other recognized business support program located in British Columbia.

These could include recent and current entrepreneurship@UBC (e@UBC) affiliated audiences, as well as BC entrepreneurs involved in UBC Library through the Innovation Library, David Lam Management 
Ticker: The Academic Business Librarianship Review, 5:1 (2020)

https://doi.org/10.3998/ticker.16481003.0005.107

(C)2020 Kim Buschert, Aleha McCauley, Nick Rochlin, Laura Thorne, and Irena Trebic

Research Library and Canaccord Learning Commons, and the Irving K. Barber Learning Centre's Small Business Accelerator Program.

Any respondents that were located outside of British Columbia were excluded from this study.

Distribution Methods. The survey was distributed via the UBC Small Business Accelerator's direct email list and social media, as well as through a blog post. It was posted to UBC's Irving K. Barber Learning Centre, David Lam Library and Okanagan Library social media channels, and a post was made on David Lam Library's blog.

The survey was also forwarded to local $\mathrm{BC}$ business librarians who were asked to share it amongst their entrepreneurship communities.

Data Collection. The survey used in this study was designed to collect both qualitative and quantitative data. All study participants were directed to a landing page which served as a consent form. The survey had a total of twenty questions. The survey was divided into four sections: demographics, general use of and attitude towards SMR, recent SMR experience (based on having done research in the past twelve months related to current venture), and library-related SMR experience.

The survey was open for eight weeks. Prior to opening it, a non-probability/volunteer sampling call was distributed in September - October 2017 via email and UBC Library social media channels.

Data was collected via UBC's survey tool, which complies with Canadian privacy laws. Participants were invited to provide their contact information to receive study findings.

\section{Findings}

A total of 36 survey responses were collected. After applying exclusion criteria, 27 responses were included. The following section provides key findings and discussion.

Demographics and business characteristics. The demographics questions were intentionally not very detailed regarding personal characteristics of the entrepreneurs themselves; the researchers were most interested in characteristics relating to their venture.

Twenty-three respondents were involved in a business venture or commercializing research in the past 12 months. Over $62 \%$ of respondents indicated that they are actively involved (over the past 12 months) in a business assistance program in BC. These may include an incubator, accelerator, or other similar entrepreneurship program located in British Columbia. Over $73 \%$ of respondents indicated that the business assistance service, incubator, accelerator, or entrepreneurship program they are involved with is affiliated with UBC. Of those who are actively involved in the business assistance program, over $70 \%$ indicated they were students. The rest indicated they were mentors, business owners, or partners.

As noted in the literature review, understanding the venture stage of entrepreneurs when they conduct SMR can help inform the services libraries provide. Given that entrepreneurs tend to need different support at different stages of their venture, they were asked to identify the stage of their 
venture at the time of responding. Figure 1 shows the business development stage of respondents. Just under half of respondents, at $44.4 \%$ (12 of 27 ) were in the Validation stage, which we defined as, "I have tested my base product or service model and have evidence that it meets needs or solves a real problem for a market I've identified." Following that was the Ideation stage, at 18.5\% (5 of 27): "I have an idea for a business but I'm not sure if it meets a need or solves a problem idea." The outliers were those respondents not developing or growing a business at $1 / 27$ each.

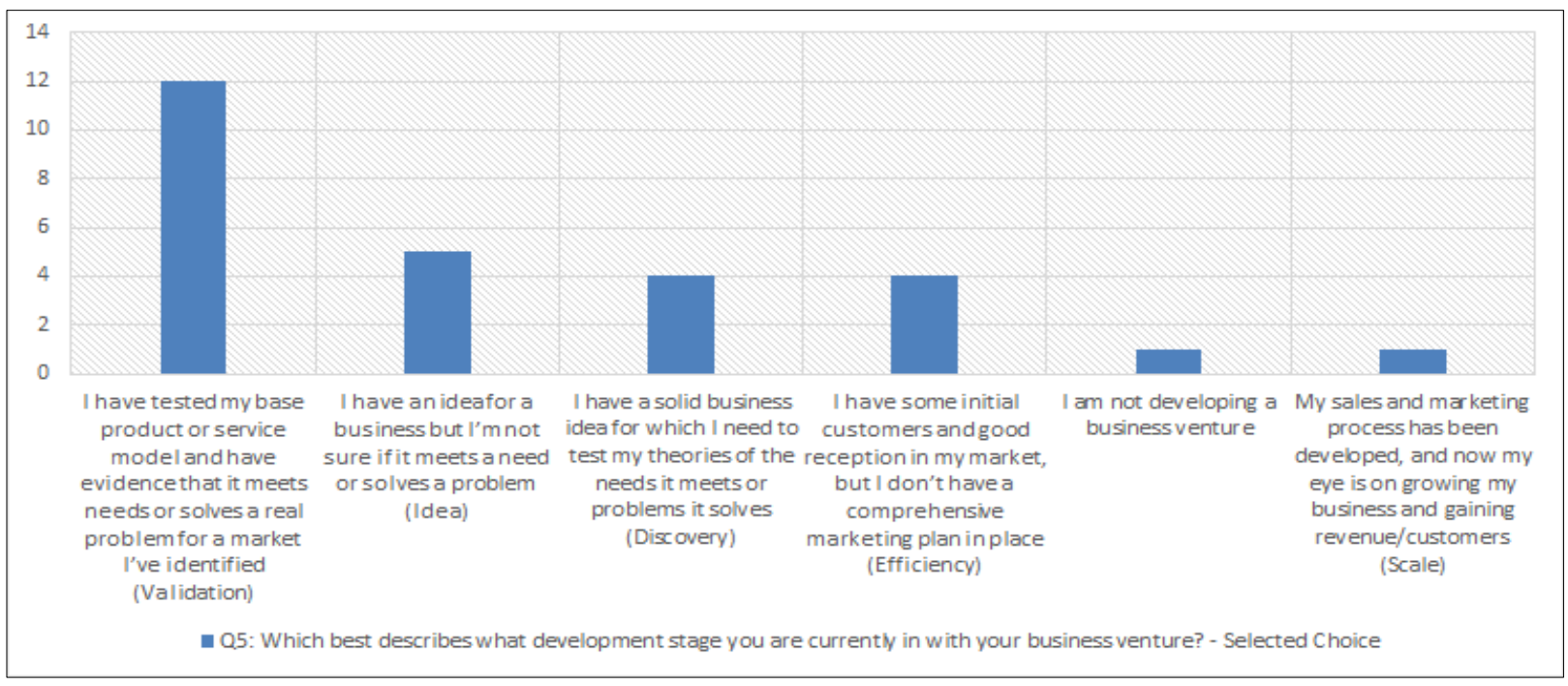

Figure 1. Respondents by venture stage

The results suggest the majority of respondents need to validate their business ideas. Secondary market research can help cement evidence of the need within the identified market and can help with the development of sales and marketing tactics. Those at the efficiency stage could similarly benefit. Entrepreneurs in the earlier stages might use SMR to understand the market in which their idea fits and learn about what customers to target for validation.

The majority of respondents (70\%) were affiliated with UBC in some way: students, alumni, and staff or program mentors. Many (75\%) had an active Campus-Wide Login, which would enable them to access UBC Library resources. The level of access to UBC resources was interesting for the researchers, as library-subscribed e-resource access for community members is restricted to in-library use. This level of affiliation is not surprising given our survey recruitment methods.

Respondents chose the industries associated with their businesses from a predefined list of 20 highlevel industry categories that we adopted from the University of Toronto's campus entrepreneurs survey. As shown in Figure 2, the top industries selected were: healthcare, business-to-business products and services, consumer products and services, and software; and tied for 5 th were food and beverage, Internet, and mobile or telecommunications. It was permissible to select more than one industry. Ten respondents chose only one industry, five selected two industries, 8 chose three industries, two selected four industries and two selected five industries. The fact that so many respondents selected multiple industries to represent their business demonstrates an entrepreneurial landscape in BC with complex ventures, spanning various industries and, therefore, markets and indicates that entrepreneurs' research needs would be equally complex for librarians to support in a research consultation. 


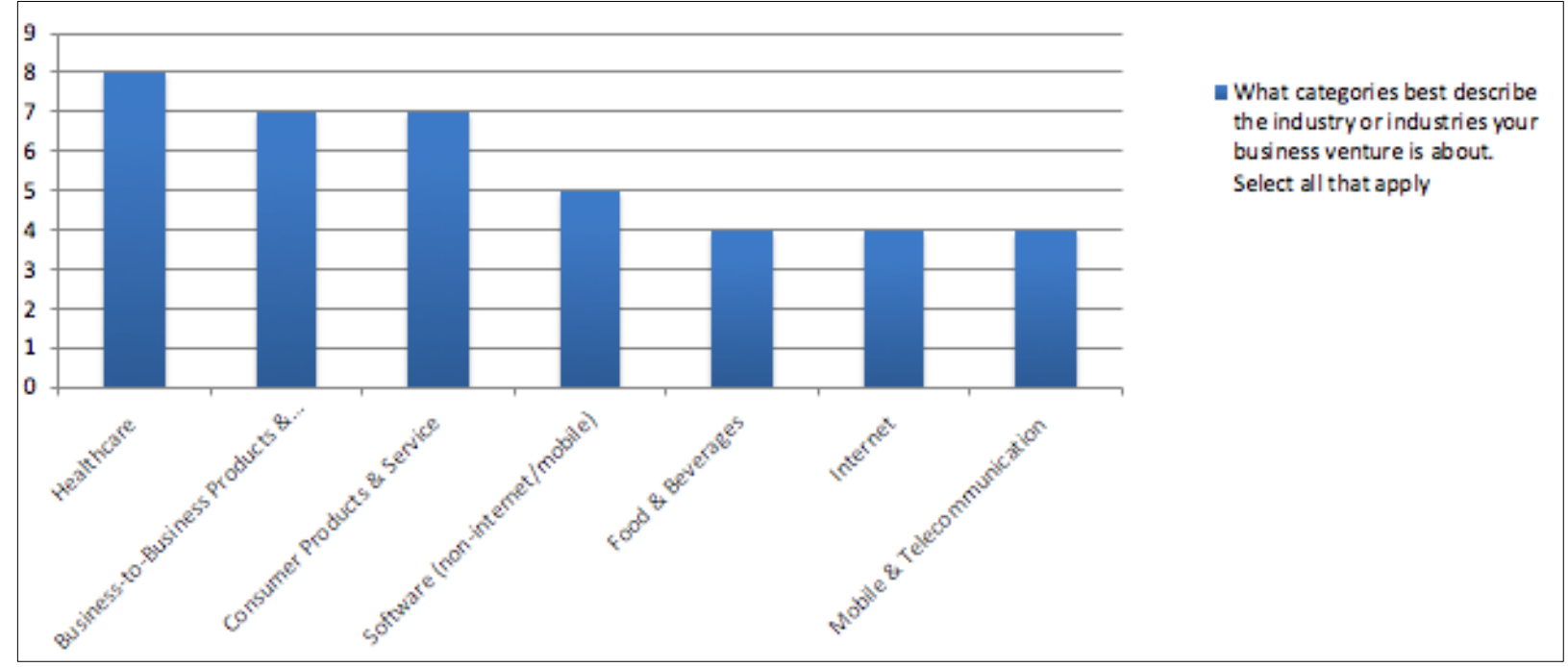

Figure 2. Respondents by industry

Having data about the industries British Columbia entrepreneurs are working in will be useful for collecting and curating SMR sources. UBC librarians working on the Small Business Accelerator as well as other entrepreneurship research guides will be able to ensure that secondary market research guides are available and kept up to date for these areas.

Experience with conducting secondary market research. The second part of the survey sought to understand BC entrepreneurs' habits when conducting SMR, from sources they use to getting help. It was of interest to the researchers to know whether the entrepreneurs had training in conducting SMR, and how they felt about various aspects of conducting SMR.

Respondents were provided with a list from which they chose the sources they use. Perhaps not surprisingly, "Google or other search engine" garnered the most results. Figure 3 shows the top-ranked responses. Other options that were included in the list, but not included below, are social media or online forums, personal subscriptions to databases, and paying a consultant to do the research.

Interestingly, two very different types of sources, asking an advisor and using UBC Library's website or database, were tied as the second-ranked selection. This could suggest an equal reliance on personal networks and reliable data sources. However, the majority of the respondent pool was affiliated with UBC in some way, which could explain some familiarity with using UBC Library resources. Other library resources were also selected; this is noteworthy in that it indicated that libraries are of use for SMR. 
Ticker: The Academic Business Librarianship Review, 5:1 (2020)

https://doi.org/10.3998/ticker.16481003.0005.107

(C2020 Kim Buschert, Aleha McCauley, Nick Rochlin, Laura Thorne, and Irena Trebic

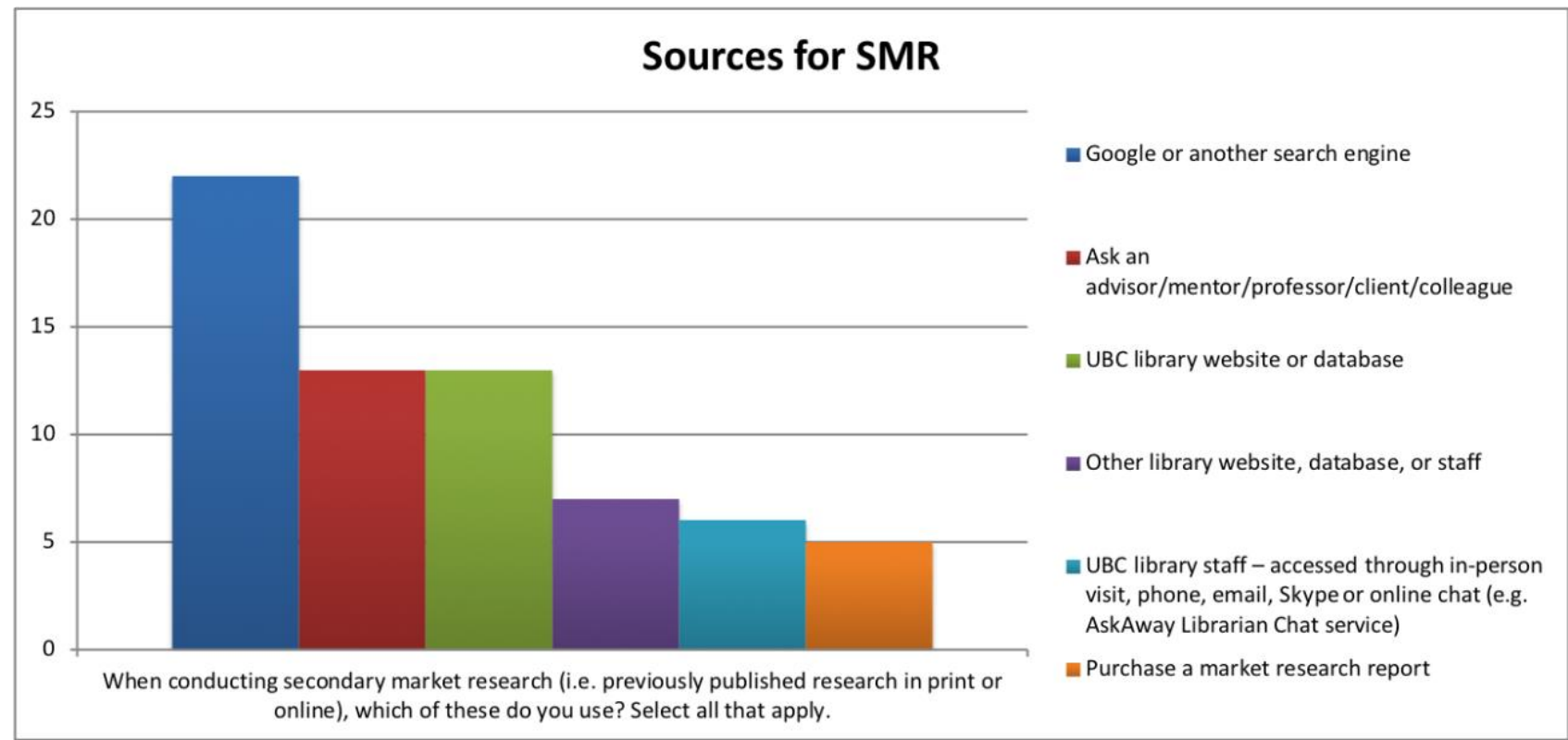

Figure 3. Top sources used for SMR

Figure 4 depicts how often respondents used different types of help for SMR. In terms of obtaining help with secondary market research, it appears that respondents don't have a source they always choose, or may use multiple sources, but may turn to an advisor/mentor/professor more often than other sources.

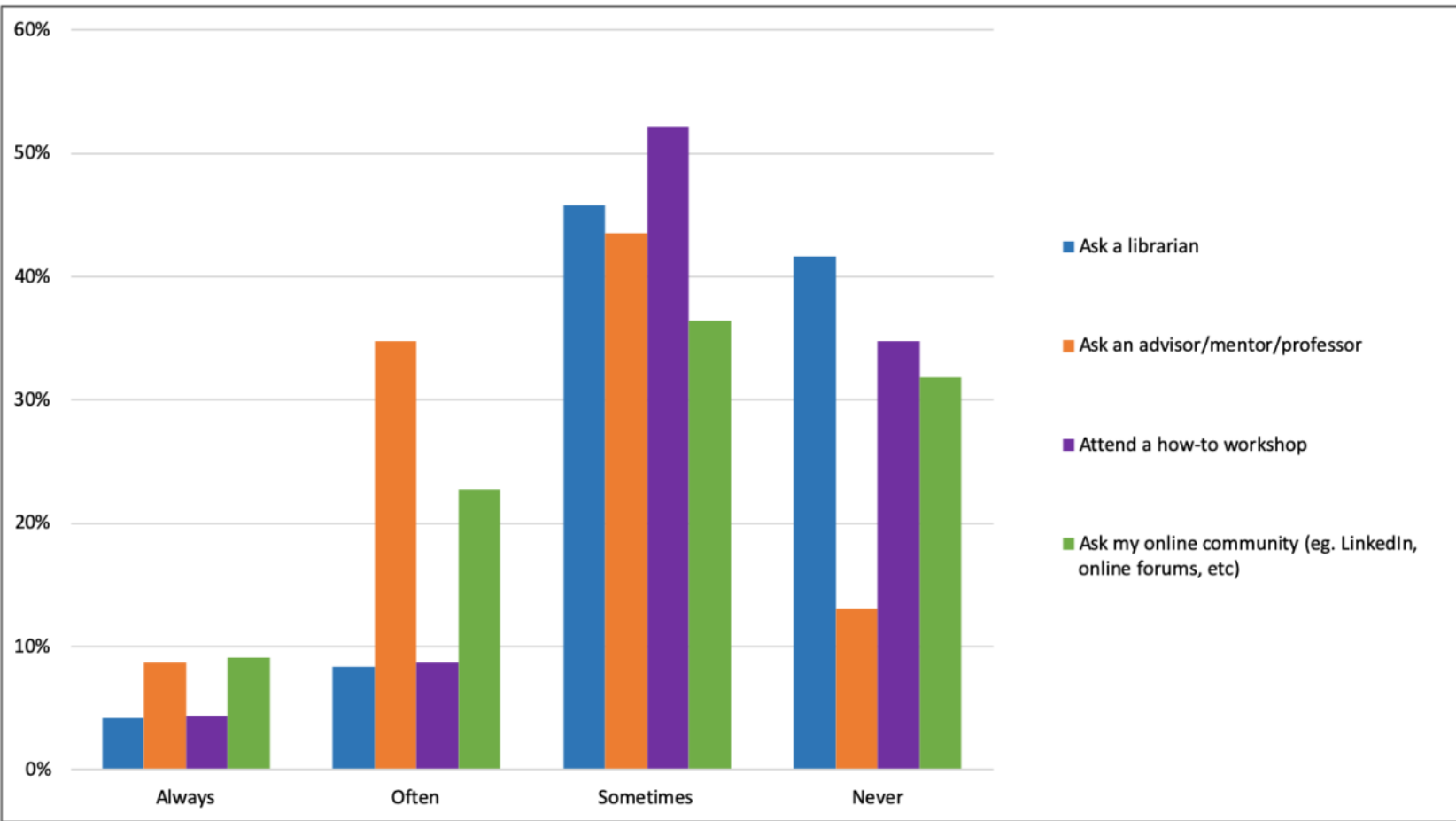

Figure 4. Respondents' methods of getting help with SMR 
Ticker: The Academic Business Librarianship Review, 5:1 (2020)

https://doi.org/10.3998/ticker.16481003.0005.107

(C)2020 Kim Buschert, Aleha McCauley, Nick Rochlin, Laura Thorne, and Irena Trebic

Librarians are asked for help sometimes or never (as opposed to always or often), suggesting we could do more to be top of mind as a trusted resource for SMR.

More than half of respondents (54\%) had training or instruction in finding secondary market resources, much of which was provided by UBC, either through for-credit courses, programs or certificates, or otherwise linked to the library. Other training respondents received was through local $\mathrm{BC}$ accelerators or non-UBC workshops or courses.

Nearly $80 \%$ of respondents denoted that they are aware that the information they need is located in many different sources (as opposed to just one source). Yet, not quite half (48\%) of respondents indicated that they have time to search for the information they need. Forty-two percent said they know how to find the information they need. Only $17 \%$ agreed that they can afford the cost of the information they need.

Business librarians' competencies in searching across disciplines and sources could help save entrepreneurs time in conducting their research. These results suggest that UBC librarians could increase their reach promoting services to entrepreneurs. Training and instruction opportunities could be marketed through local accelerators or assistance programs and to business advisors, as these are well-linked to entrepreneurs. Our results show that promoting market research collections is also important; libraries' subscriptions to costly market research reports can help entrepreneurs access information they wouldn't otherwise be able to afford.

Most recent experience conducting SMR. The third section of our survey asked participants to recall a time in the past 12 months that they had conducted SMR.

Respondents who indicated having done research in the last 12 months signified that the top three reasons SMR was required include preparing/revising a business plan, re-evaluating their course of action (e.g. pivoting to new market), and preparing for a pitch competition or similar funding opportunity.

The type of information prioritized was company or competitor information (82\% ranked this as high priority), consumer information ( $77 \%$ ranked as high priority), and industry information (64\% ranked as high priority).

Knowing the reasons why entrepreneurs conduct SMR and the type of information they prioritize is particularly helpful to ensure the library has access to relevant resources and that librarians promote the availability of these resources. For instance, Gale's Business Plans Handbook, a resource that is subscribed to by many libraries in $\mathrm{BC}$, should be very useful for those looking for information on developing a business plan. Articles and books about pivoting and succeeding at venture capitalist pitches can be curated and highlighted through guides and blog posts as well.

Respondents were asked to depict the information they obtained. Did it precisely answer their question (32\% agreed), or was it generalizable to their question ( $73 \%$ agreed)? Were they satisfied with its accuracy ( $27 \%$ agreed) and currency ( $41 \%$ agreed)? Was it from a trusted source (64\% agreed)? And finally, would they spend the time again to find similar information for another venture ( $86 \%$ agreed)?

Further, they were asked about various impacts the information found had on their business. A total of $76 \%$ agreed that it contributed to a better product or service, and $64 \%$ said it revealed a new opportunity about the market or venture. Just under half (48\%) agreed that the information supported a 
Ticker: The Academic Business Librarianship Review, 5:1 (2020)

https://doi.org/10.3998/ticker.16481003.0005.107

(C)2020 Kim Buschert, Aleha McCauley, Nick Rochlin, Laura Thorne, and Irena Trebic

claim they were already making about their venture. Another $45 \%$ agreed that the information caused a pivot or shift in the venture, and $40 \%$ agreed that the information helped them to raise funds or sign on partners or investors. Seventy-five percent of respondents acted differently than they would have if they had not had the information.

Despite lower satisfaction regarding accuracy and currency of the information, the respondents generally found SMR to be time well spent. The information obtained contributed to important changes, such as identifying new opportunities, and caused the researchers to act differently.

Library support. In the fourth and final section of the survey, respondents who indicated they had used the library in their research were asked what was most valuable about the library. This was a written response question; comments were coded into two broad categories. The first category was collections and included responses such as databases $(n=6)$, market research reports $(n=2)$, industry information $(n=5)$, books $(n=1)$, and demographics $(n=1)$. The second category was people/tools and included responses such as advice and knowledge of librarians $(n=2)$, workshops $(n=1)$, and online databases $(n=6)$. Additional comments included a need for more workshops and databases and participants' lack of certainty about where to start their research.

Respondents who had not used the library for their research were asked about their reasons for not doing so. The main three responses were that they were not aware of services to support SMR $(n=5)$, they did not know who to contact $(n=5)$, and the library they have access to doesn't offer services for entrepreneurs $(n=3)$. Additional comments indicated that respondents did their own competitive analysis or primary research. They noted a need for more specific British Columbia information, as well as information that was not available in either databases or library-provided reports. "Other" responses indicated that they would like to work continuously with a librarian specializing in entrepreneurship (who may or may not be able to do their research for them).

Respondents value the library's collections and its people; however, the results to the earlier question about getting help indicated that librarians were "sometimes" to "never" contacted to assist with SMR. Responses to our follow-up question of respondents who did not indicate that they used the library for SMR brought forth that they didn't know the library offered such assistance, as well as that they did not know whom to contact at the library. These results point to a need for increased, targeted marketing to BC entrepreneurs, including a point-of-entry contact.

\section{Conclusion}

The results of this study provide data in some key areas for developing and improving UBC Library's services for entrepreneurs.

The results of this study will help us assess the effectiveness of UBC Library's current array of research assistance for BC entrepreneurs. Furthermore, we have learned about unmet needs that could lead to new opportunities for UBC Library to support both campus-based and community entrepreneurs. The findings have the potential to influence how UBC Library collections purchasing, selection and renewal decisions are made, as well as to inform content of curated resources. Our findings provide us with an improved understanding of the different user groups in our entrepreneurial ecosystem. 
The information respondents found through SMR was attributable to important business shifts and improvements. However, accuracy, time to search, and the high cost of information can be barriers. These are all problems that the library can alleviate through its collections and services; librarians' expertise in directing entrepreneurs to commercial sources available through library subscriptions and to high-quality freely-available market research sources should be particularly valuable.

The findings present opportunities for UBC librarians to create innovative services to attract and engage with entrepreneurs more completely and to provide value-added service. In order to meet the needs of BC entrepreneurs, possible considerations for librarians include targeting early-stage entrepreneurs (especially for library workshops), exploring access options and collections for entrepreneurs, developing and promoting online services, and having a service model with a single service entry point for entrepreneurs. Thorough marketing of entrepreneurial services is needed to ensure that the library is seen as a valuable resource. In addition to developing services and collections, forming partnerships with campus groups, community agencies, and business groups is another way to increase awareness of library support for entrepreneurs.

More broadly, the researchers hope that sharing the results of this study might increase general understanding of entrepreneurs' library use patterns, needs, and research preferences. We anticipate this study will continue to lay the groundwork for future research in this area. It is our hope that others will conduct studies to address gaps based on the areas of limitation identified in this study and will build a more comprehensive picture of how academic libraries can support the research and informational needs of local entrepreneurs.

Reflections and lessons learned. The librarians involved in this study were all novices at designing methodology, designing surveys, and analyzing results. Furthermore, there is no dedicated time for research within our roles; however, our head librarians were supportive of the learning opportunity this study presented. The researchers benefited greatly from a librarian on study leave generating the idea, leading the organization of the group's meetings, and keeping everyone on track. Having a student librarian through a for-credit research collaboration course provided capacity for conducting the literature review. Without these resources and librarians having dedicated time to contribute, finding the time for this project would have been extremely difficult.

Upon initiating the study, we sought approval from the UBC Behavioral Research Ethics Board (BREB). This required preparing an extensive package of information, including information about our study, our recruitment methods, and our data protocols. However, upon submission the BREB informed us that our study could be considered a quality improvement study. In Canada, the Tri Council Policy Statements provide guidance on ethical conduct in research involving humans, and these specify that quality improvement and quality assurance studies that are "used exclusively for assessment, management or improvement purposes" do not require ethics approval (Government of Canada Panel on Research Ethics, 2018, article 2.5). Given the purposes of our study, we opted not to proceed with BREB review. While undergoing this process was useful as a learning opportunity and helped us fully develop our project, we recommend consulting with an institutional research ethics board for advice prior to submitting a proposal that could be considered quality improvement.

Following the information-gathering stage, the study leave ended, as did the student's course. One of our librarians left the university the following year. Not surprisingly, then, it was a challenge to find time 
Ticker: The Academic Business Librarianship Review, 5:1 (2020)

https://doi.org/10.3998/ticker.16481003.0005.107

(C)2020 Kim Buschert, Aleha McCauley, Nick Rochlin, Laura Thorne, and Irena Trebic

within the academic year to analyze and write up results, contributing to a long delay in writing and a need to update the literature review and to carefully review findings. We would recommend ensuring time is dedicated to the writing stage when considering project timelines.

Limitations. Using a self-selecting non-probability sample approach likely limited the size of the sample. Some business owners may not identify as entrepreneurs, and some entrepreneurs may not identify their information-seeking as secondary market research, despite our attempt to define both terms in the survey. The distribution methods were likely to reach mainly UBC-affiliated entrepreneurs, to the exclusion of entrepreneurs in BC not affiliated with UBC in some way.

Opportunities for future research. Other areas of future research that are outside the scope of this study include:

- Further exploration on the information-seeking behavior of Canadian entrepreneurs by industry or during specific venture stages beyond start-up;

- Investigations of motivations behind primary vs. secondary research methods of obtaining information;

- Investigation into the perceived value of information competence in entrepreneurs and small to medium-sized enterprises;

- Exploration of the influence of "information behavior" on small business failure;

- Investigation of the perceived value of library assistance or provided information for entrepreneurs with business ventures;

- Investigation of any differences in information-seeking behavior between first-time and experienced entrepreneurs. 
Ticker: The Academic Business Librarianship Review, 5:1 (2020)

https://doi.org/10.3998/ticker.16481003.0005.107

(C)2020 Kim Buschert, Aleha McCauley, Nick Rochlin, Laura Thorne, and Irena Trebic

\section{References}

Collins, B. (2012, August 13). How public libraries are a boon to small business. American Libraries. https://americanlibrariesmagazine.org/2012/08/13/how-public-libraries-are-a-boon-to-small-business/

Daniel, J. (2012). Sampling essentials: Practical guidelines for making sampling choices. Thousand Oaks, CA: SAGE Publications Ltd. https://doi.org/10.4135/9781452272047

Enis, M. (2012). Mapping out a plan: With affordable new GIS software, libraries can help local entrepreneurs build more successful businesses. Library Journal, 137(15), 22. https://www.libraryjournal.com/?detailStory=mappingout-a-plan-product-spotlight

Erzetič, B. H. (2008). Means of knowledge acquisition of entrepreneurs and their success. Managing Global Transitions, 6(2), 157-175. http://www.fm-kp.si/zalozba/ISSN/1581-6311/6_157-175.pdf

Feldmann, L. M. (2014). Academic business librarians' assistance to community entrepreneurs. Reference Services Review, 42(1), 108-128. https://doi.org/10.1108/RSR-04-2013-0021

Franks, J. E., \& Johns, C. (2015). Entrepreneur assistance \& economic development in Florida libraries. Reference Services Review, 43(3), 400-418. https://doi.org/10.1108/RSR-03-2015-0014

Fust, A., Wustrow, P., \& Fueglistaller, U. (2015). Entrepreneurs' information search behavior in SMEs: Development of a scale. In T. Cooney (Ed.), Entrepreneurship \& Sustainability: Proceedings from ICSB 2014 World Conference (pp. 1-3). Dublin: Dublin Institute of Technology. https://icsb.org/wpcontent/uploads/2017/07/ICSB2014_CD_Proceedings.pdf

Głodek, P. (2018). Cooperation and small business advisory process. Przedsiębiorczość i Zarządzanie 7(3), 483-497. https://www.ceeol.com/search/article-detail?id=716311

Government of Canada Panel on Research Ethics. (2018). TCPS 2 (2018) - chapter 2: Scope and approach. https://ethics.gc.ca/eng/tcps2-eptc2_2018_chapter2-chapitre2.html

Griffis, P. (2015). Academic libraries as community resource partners for entrepreneurs . Reference Services Review, 43(3), 461. http://dx.doi.org/10.1108/RSR-06-2015-0028

Hoppenfeld, J., \& Malafi, E. (2015). Engaging with entrepreneurs in academic and public libraries. Reference Services Review, 43(3), 379. https://doi.org/10.1108/RSR-02-2015-0011

Jiao, H., Cui, Y., Zhu, Y. and Chen, J. (2014) Building entrepreneurs' innovativeness through knowledge management: The mediating effect of entrepreneurial alertness. Technology Analysis \& Strategic Management, 26(5), 501-516. https://doi.org/10.1080/09537325.2013.872774

Lackéus, M., \& Williams Middleton, K. (2015). Venture creation programs: Bridging entrepreneurship education and technology transfer. Education + Training, 57(1), 48-73. https://doi.org/10.1108/ET-02-2013-0013

Macdonald, A. T. (2015). Dedicated business centers in public libraries. Reference Services Review, 43(3), 344-368. https://doi.org/10.1108/RSR-02-2015-0007

Mueller, S., Volery, T., \& von Siemens, B. (2012). What do entrepreneurs actually do? An observational study of entrepreneurs' everyday behavior in the start-up and growth stages. Entrepreneurship Theory and Practice, 36(5), 995-1017. https://doi.org/10.1111/j.1540-6520.2012.00538.x 
Ticker: The Academic Business Librarianship Review, 5:1 (2020)

https://doi.org/10.3998/ticker.16481003.0005.107

(C)2020 Kim Buschert, Aleha McCauley, Nick Rochlin, Laura Thorne, and Irena Trebic

Neck, H.M. \& Greene, P.G. (2011). Entrepreneurship education: Known worlds and new frontiers. Journal of Small Business Management 49(1), 55-70. https://doi.org/10.1111/j.1540-627X.2010.00314.x

Reynolds, P.D. \& Curtin, R.T. (2011). United States: Panel Study of Entrepreneurial Dynamics I, II Overview. In P.D. Reynolds and R.T. Curtin (Eds.), New business creation: An international overview. New York, NY: Springer.

Shabaya, R. (2014). Factors that influence entrepreneurs to seek external expertise (Doctoral dissertation). Retrieved from ProQuest Dissertations and Theses Global. (Dissertation no. 3614528)

Soetanto, D. (2017). Networks and entrepreneurial learning: Coping with difficulties. International Journal of Entrepreneurial Behavior \& Research 23(3), 547-565. https://doi.org/10.1108/IJEBR-11-2015-0230

Sullivan, D.M. \& Ford, C.M. (2014). How entrepreneurs use networks to address changing resource requirements during early venture development. Entrepreneurship Theory and Practice, 38(3), 551-574.

https://doi.org/10.1111/etap.12009

Tang, J. (2016). Linking personal turbulence and creative behavior: The influence of scanning and search in the entrepreneurial process. Journal of Business Research, 69(3), 1167-1174. https://doi.org/10.1016/j.jbusres.2015.09.017

Torrance, W.E.F. (2013). Entrepreneurial campuses: Action, impact and lessons learned from the Kauffman Campus Initiative. https://www.kauffman.org/wp-content/uploads/2019/12/entrepreneurialcampusesessay.pdf

Yin, M. \& Jahanshahi, A.A. (2018). Developing knowledge-based resources: The role of entrepreneurs' social network size and trust. Sustainability, 10(10), 3380. https://doi.org/10.3390/su10103380

Yusuf, J. (2010). Meeting entrepreneurs' support needs: Are assistance programs effective? Journal of Small Business and Enterprise Development, 17(2), 294-307. https://doi.org/10.1108/14626001011041283 